\title{
Identidad y baja visión
}

Morel Graciela* - Villalobos Laura**

\section{Presentación}

En el presente ensayo nos proponemos desarrollar la temática de la identidad en las personas con baja visión. Hemos elegido el tema porque nos parece muy interesante cómo la persona, una vez adquirida la discapacidad e iniciado el proceso de rehabilitación, en realidad lo que necesita es trabajar en la "construcción de una nueva identidad" que le permita reconocerse cómo es actualmente: un sujeto con posibilidades y limitaciones.

Observamos que mientras no comience ese proceso de aceptación de sí mismo, no puede iniciar su trabajo desde la discapacidad y queda "sujetado" a su estado anterior, un estado que ya no existe y que sumerge al participante en un anhelo por el pasado que no le permite al sujeto proyectar un futuro real, acorde con su situación actual.

Cuando una persona adquiere la discapacidad visual, el conocimiento y reconocimiento que tiene de sí mismo y ante los demás se ve altera- do. Va a "desconocerse" porque todo lo que sabe de él, ya no lo encuentra... y los demás tampoco.

Así, creemos importante analizar qué es la identidad, indagar sobre los procesos que intervienen y factores que influyen en su construcción, para luego relatar desde nuestra práctica profesional (rehabilitadoras de personas que han adquirido discapacidad visual en ASAC), cómo la identidad se ve afectada cuando una persona tiene esta discapacidad.

\section{¿Qué es la baja visión?}

La Organización Mundial de la Salud (OMS) dice que un sujeto con baja visión "es quien aún después de un tratamiento y/o refracción convencional tiene en su mejor ojo una agudeza visual de 3/10 hasta visión luz y/o un campo visual menor o igual a $20^{\circ}$, pero que usa, o es potencialmente capaz de usar su visión para planificar o ejecutar una tarea".

* Laura Villalobos es directora de Orientación y Movilidad en la Asociación de Ayuda al Ciego (ASAC) de la Cap. Federal, Argentina. Consultora en Orientación y Movilidad para la región latinoamericana de International Council for Education of People with Visual Impaiment (ICEVI). Profesora de la maestría en Educación Especial, mención en Educación de las Personas con Discapacidad Visual, en la Universidad Politécnica Salesiana (UPS).

** Graciela Morel es vicedirectora del Centro de Rehabilitación ASAC (Asociación de Ayuda al Ciego) en Argentina y profesora de discapacitados visuales. 
¿Qué significa tener baja visión? Es permanecer en un estado ambivalente donde no hay ni ausencia ni presencia total de visión, algunas cosas se ven y otras no.

A veces imagino que mis yoes más jóvenes están sentados conmigo a la mesa. Les digo que aceptar la ceguera ha significado algo que antes no podía ni imaginar. Reconocer que veo muy poco me da poder, porque el mundo es más accesible y me acoge con más generosidad que cuando simulaba ver. Pero en otro sentido también es difícil. Dondequiera que vaya llamo la atención y a veces me siento enterrado bajo el graffiti de las supersticiones de los demás (Kuusisto, 1999: 205).

Si consideramos a la persona con baja visión como a alguien aprisionado entre el mundo de los ciegos y el mundo de los que ven, podemos entender esta peculiar experiencia. La persona debe formar una identidad basándose en un grupo que la sociedad aún no reconoce, por manejarse en la dicotomía de ver y no ver. "Yo me acuerdo que de pequeña ponía a prueba mi capacidad visual. ¿Cuándo parecía más discapacitada visual? ¿Podía arreglarme para ser menos discapacitada para una situación determinada? Y ¿cuánto más me asemejaba a una persona con visión normal?" (Corn, 1993: 9).

Cabe señalar que la leyenda más célebre sobre la ceguera quizás sea la de Tiresias. Se dice que Hera y Zeus discutían sobre si los hombres o las mujeres obtenían más placer sexual, para lo cual deciden consultar a Tiresias, un mortal que como consecuencia de un hechizo había sido hombre y mujer. Él confirma la afirmación de Zeus (que son las mujeres las que obtienen mayor placer) y Hera, que no le agradaba perder en sus discusiones, lo ciega. Zeus se compadece de él, y aunque no puede curarlo, le concede el don de ver el futu- ro. La ceguera física de Tiresias queda eclipsada por su don.

Ninguna persona ciega puede ignorar las espinas de inquietud que lo salpican en el terreno metafísico, ya que junto a la ceguera hay toda una serie de mitos y leyendas que contribuyen a generar otras expectativas o fantasías, pero al mismo tiempo le incitan a aceptar su pertenencia a ese mundo.

En nuestra práctica, lo que realmente observamos es que quienes padecen baja visión 'prefieren' pasar por una situación de riesgo, de negación, incluso poniendo en riesgo sus vidas; antes que aceptar su condición ante los demás. En este punto nos parece importante profundizar la mirada e identificar los elementos que pueden favorecer la aceptación de sí mismo y la construcción de esa nueva identidad.

\section{Aproximaciones al concepto de identidad}

Esta necesidad de un sentimiento de identidad es tan vital e imperativa, que el hombre no podría estar sano si no encontrara algún modo de satisfacerla

Erich Fromm

El concepto de identidad tiene diferentes significados y se utiliza en una variedad de contextos que intentaremos distinguir para evitar confusiones.

Un primer significado se encuentra en la tradición metafísica y aristotélica, que la concibe como uno de los principios fundamentales del ser. El principio ontológico de "no contradicción" afirma que todo ser es idéntico consigo mismo $(\mathrm{A}=\mathrm{A})$, o sea que una cosa no puede ser y no ser al mismo tiempo y desde un mismo punto de vista. Como una regla del pensamiento lógico, el principio de identidad establece que dos proposiciones contradictorias no pueden ser falsas o verdaderas al mismo tiempo 
y que una idea contradictoria (un triángulo redondo) no tiene sentido. Como propiedad de los seres, la identidad no implica que ese ser particular sea capaz de reflexión (un cuadro es idéntico a sí mismo lo mismo que el ser humano, aunque el cuadro no tenga conciencia de ello y el ser humano sí).

Para muchos filósofos modernos el pensamiento reflexivo era crucial para la identidad humana y marcaba la diferencia con la identidad de las cosas y los animales, el problema era establecer qué era lo que garantizaba ese autoconocimiento en el tiempo.

En ambas variantes vemos que la identidad se reduce a un problema de mismidad: cómo el sujeto se 're-conoce' a sí mismo a través del tiempo y puede así dar cuenta de sus actos, lo que nos enfrentaría a un problema moral y de responsabilidad.

La concepción filosófica moderna creía en la existencia de un sí mismo, que emerge con el nacimiento, como alma o esencia, y que permanece igual toda la vida. Pero muchos sociólogos y psicólogos sociales han desarrollado otra concepción, en donde las expectativas de los otros juegan un rol importante en el proceso de identificación con algunas cualidades. Así hablamos de un sujeto producido en interacción con otros y que se va construyendo en esa interacción; ya no será la identidad un proceso que tenga un fin, sino una construcción que acompañe al sujeto a lo largo de su vida.

A su vez es interesante notar que yendo en esa dirección el individuo asume identificaciones personales, que a su vez van siendo menos personales y más generales. Se irá identificando con categorías más amplias que contribuirían a su 'despersonalización' o 'autodesconocimiento'.

Michel Foucault parte de los preceptos "conócete a ti mismo" y "ocúpate de ti mismo", para hacer referencia a las relaciones entre el conocimiento de uno mismo y el cuidado de uno mismo. Toma la épiméleia (Foucault, 2001)

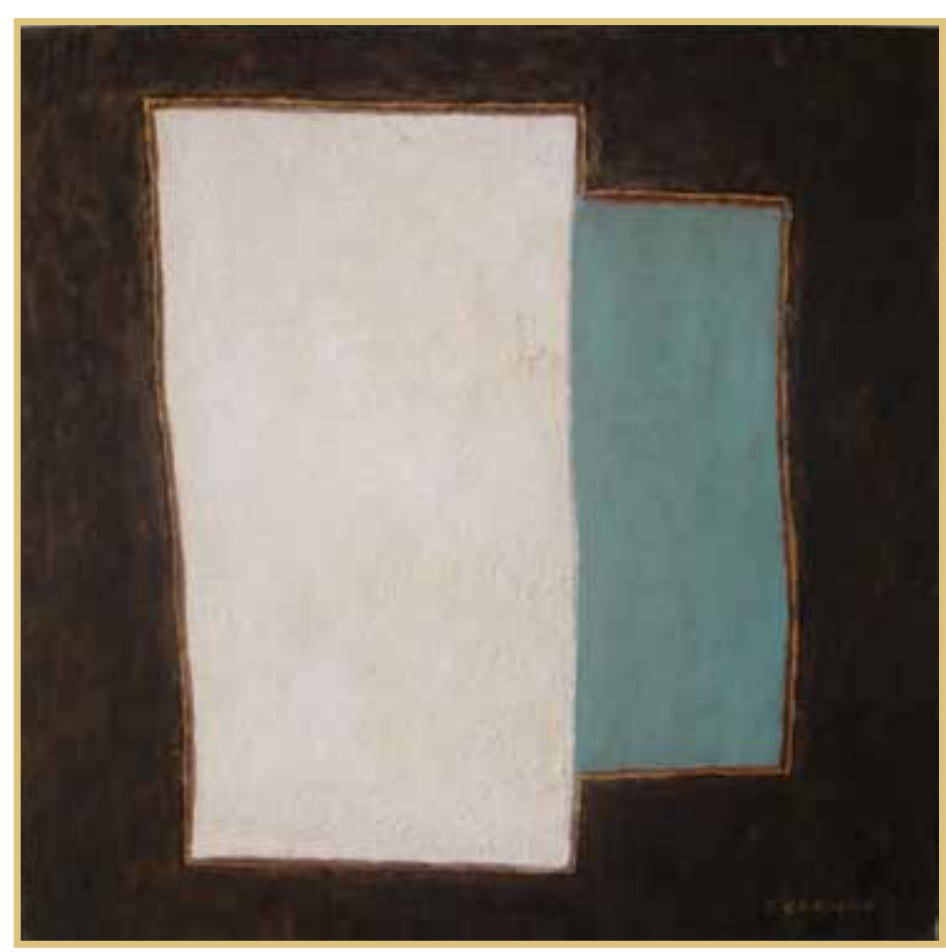

Abrazo $40 \times 40 \mathrm{~cm}$ 


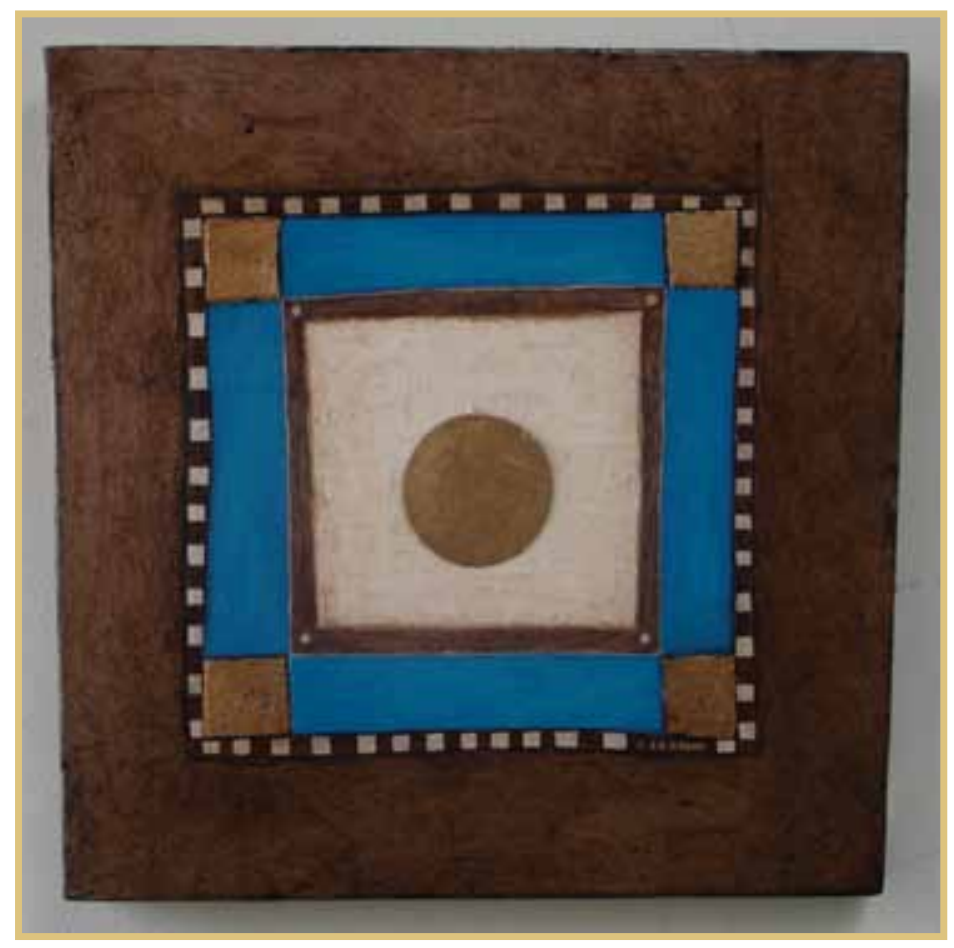

Sol -2006

$30 \times 30 \mathrm{~cm}$ como principio básico para cualquier estilo o forma de vida y distingue en él varios aspectos:

- Es una actitud general, un modo de comportarse con respecto a uno mismo, a los otros y al mundo.

- Es una determinada forma de atención, de mirada. Preocuparse por uno mismo implica que uno reconvierta su mirada y la desplace desde afuera hacia sí.

- Señala una forma de actuar, haciéndose cargo de sí mismo, se modifica, se purifica, se transforma, se transfigura.

- Implica un corpus que define una manera de ser, una actitud.

Según Foucault, el ocuparse de uno mismo se relaciona con la necesidad de cierto conjunto de prácticas que transformen el modo de ser del sujeto, un ser en la libertad con dominio en sí mismo. "Cada uno puede adoptar su propio estilo de vida, es decir, su propia técnica de subjetivación, y que para ello no hay recetas" (Foucault, 2001). Todos los ejemplos se deben dar en el contexto propio. Foucault evita toda normativa e invita a que usemos nuestra libertad para dar un estilo a nuestra propia vida.

Para la psicología, la identidad es una necesidad básica del ser humano (su construcción), que nos permite responder a la pregunta ¿quién soy yo?, y es tan necesaria como recibir afecto o alimentarnos. La respuesta que se logra no es absoluta y siempre está cambiando, pero nunca dejamos de buscarla.

Se puede afirmar que la identidad tiene que ver con nuestra historia de vida, influida por el concepto de mundo que predomina en la época y lugar en que vivimos. Hay un cruce entonces entre individuo, grupo de pertenencia y la historia social e individual.

"El ser humano en proceso de desarrollo se interrelaciona no solo con un ambiente natural determinado sino también con un orden 
cultural - social específico, mediatizado para él por los otros significantes a cuyo cargo se halla" (Berger y Luckmann, 1986).

Es decir que no habría un solo 'nosotros', sino varios, no excluyentes, superpuestos en el 'uno mismo'. Así es como decimos: nosotros los seres humanos, nosotros los argentinos, nosotros los docentes.

Es notable observar cuando el sujeto pierde ese grupo que le permite identificarse, que le ayuda a responder a la pregunta ¿quién soy?, pues queda en una situación de paria, (en la introducción a la obra de Hannah Arendt, el profesor Manuel Cruz hablará de outsider), es decir, una persona con una actitud enfermiza para asimilarse al mundo donde se halla, de modo que está dispuesto a negarse a sí mismo con tal de no sentirse separado de él (retomaremos esta idea cuando abordemos la identidad de la persona con baja visión).

Continuando, toda identidad va cambiando y supone alteridad, hay un 'otro' que me confirma mi identidad (alteridad-otredad). La necesidad de afiliación es ser parte, sentirse reconocido por el sentido de pertenencia.

Se puede decir que la identidad es evolutiva y está en proceso de cambio permanente, presenta crisis y pérdidas; lo que afirma la existencia de particularidades, pero también de diferencias y relaciones con los otros.

Conformar una identidad es establecer un centro de gravedad en torno a sí mismo, que implica que más allá de los cambios internos y externos, de los saberes nuevos incorporados, hay un Yo relativamente unificado, con una posición básica de ser en el mundo que lo acompañará a lo largo de toda su vida, por encima de los ajustes y replanteos que deba hacer de acuerdo a las circunstancias sociales y particulares.

Construir nuestra identidad es un trabajo con un doble sentido: por un lado, darnos ese sentimiento de unidad y por otro, singularizarnos con respecto a los otros. Arendt habla de 'acción' como algo inherente a la condición humana, reconociendo en ella aquello que el hombre hace para distinguirse de los demás y crea la "condición para el recuerdo". De un modo, esto se va a relacionar con la idea de muerte y cómo podemos trascenderla: a través de nuestros actos en el ámbito de lo público (res publica), en aquellos espacios que se comparten con otros.

Así, hay una identidad como totalidad, como universo, que incluye varios subsistemas:

- Identidad sexual o de género: implica asumir las cuestiones inherentes al sexo biológico, lo femenino y masculino, el rol de hombre o de mujer y su relación con el otro.

- Identidad física: implica lo que tiene que ver con el propio cuerpo y su relación con lo otros (por ejemplo el tema de la obesidad); estará íntimamente ligado a lo que dicen los otros de su cuerpo.

- Psicológica: relacionados con los sentimientos hacia uno mismo (autoestima y autoconocimiento). Estructura de la personalidad.

- Social: grupo social de pertenencia (clase social), grupo primario y secundario de interacción (familia, amigos, compañeros). Los grupos actúan como redes de apoyo, son el medio a través del cual se conforma "el otro socializado", que es el reconocimiento del conjunto de reglas, costumbres y características específicas del medio social al cual el individuo pertenece.

- Moral: tiene que ver con el conjunto de creencias que rigen la acción del sujeto, se puede hablar de códigos de ética personal.

- Ideológica: filosofía de vida.

- Vocacional: proyecto de vida, realización de una vocación.

Consideramos que estos subsistemas no tienen igual preponderancia siempre, sino que de acuerdo al momento que el sujeto viva, unos 
tendrán más o menos supremacía sobre otros. El ejemplo clásico tiene que ver con el fin del ciclo de escolaridad obligatoria y el planteamiento de una actividad a realizar. Esto a su vez estará muy influenciado por el medio al que pertenece el sujeto ya que allí estará ese poder de decisión 'sujetado' a otros elementos determinantes.

Teóricamente, la 'realización' de estos subsistemas le permitiría al sujeto lograr el ansiado equilibrio y por ende, la conformación de una 'identidad sólida'. Aunque desde nuestro punto de vista, si hablamos de identidad como algo no acabado, sino como una construcción que acompaña al sujeto durante toda su vida, tenemos que pensar que ese 'equilibrio' es imposible de alcanzar, ya que de ser así, estaríamos aceptando un 'determinismo' donde el sujeto tendría un camino trazado por metas predeterminadas, cuyo logro implicaría alcanzar la plenitud.

Como vemos, este sentimiento de unidad es complejo en su conformación, tiene muchos proceso internos más o menos intrincados; pero en general, cada sujeto logra una síntesis relativamente completa de estos distintos aspectos que conforman la identidad, sin por eso creer que dicha síntesis sea estable, ya que está sujeta a cambios más o menos permanentes de acuerdo al momento social e histórico del individuo.

\section{Cuando la identidad 'sufre ataques'}

Seguramente el hombre, como sujeto humano, si bien defiende su libertad de decidir, por otro lado también se aferra a cierto determinismo como una defensa ante lo que 'puede' venir. Esa imposibilidad de manejar el futuro siempre nos induce a aferrarnos a lo que tenemos, a eso que somos y que deseamos se mantenga de la misma manera.

Pero ante lo inesperado o lo no deseado, se produce el conflicto entre lo que quiero ser y lo que se me impone desde mis circuns- tancias. Seguramente, si tenemos en cuenta la importancia del 'otro social' en la formación de la identidad, también será muy importante lo que esa situación implique en su medio. Un ejemplo podría ser lo que implica para el sujeto joven de hoy decidir cambiar de vocación. En la actualidad no se espera que la persona tenga una vocación única ni que la mantenga, de hecho, se espera que explore varias alternativas.

Lo que decimos es que será fundamental cómo el entorno social del sujeto (alteridad) considere esa situación nueva que se le presenta este. Específicamente si hablamos de discapacidad, donde tenemos una 'construcción social' negativa, será muy difícil para la persona aceptar esa situación, incluirla entre sus características o cualidades y 'reconstruir su identidad', antes de pensar en un proyecto posible.

Nos viene a la memoria las palabras de Kuusisto: “iquién quiere ser ciego?” La decisión pasa por la negación de la situación y por intentar 'simularla', lo cual no solo alcanza al medio, sino que impregna también al mismo simulador ya que la devolución de los otros es la de un sujeto con vista, por lo que termina 'creyendo esa situación', es decir, Tiresias finalmente supera la ceguera.

No es nuestra intención plantear el "constructo social sobre la discapacidad" ni investigarlo, eso nos parece pertinente para otro trabajo; pero sí es importante ahondar sobre lo que hemos observado en nuestra práctica, intentando buscar posibles causas a ese modo de sobrellevar la discapacidad.

\section{El sujeto 'sujetado': una situación nueva}

La alteración de uno de los subsistemas que conforman la identidad de una persona indirectamente modifica a los demás. Queremos hacer hincapié en un aspecto importante relacionado con cómo se altera el proyecto de vida de una persona de edad media ( 40 a 50 años) que 
adquiere esta discapacidad y cómo esto le afecta de tal manera que cae en una crisis generalizada, sumergiéndola en un tiempo sin tiempo ni acción, en un 'estar detenido' en medio de un caos individual, donde "todo lo que creía seguro se vuelve inestable y la sensación es que caí en un pozo del que no puedo escapar y lo que espero es curarme".

$\mathrm{Su}$ identidad se restringe solo a aspectos corporales, a sus habilidades y al contexto familiar.

Arendt plantea que la "Condición Humana” está conformada por labor-trabajoacción. Labor tiene que ver con los procesos biológicos, ligados a necesidades vitales que aseguran la permanencia individual y de la especie (alimentación y vestimenta por ejemplo). Trabajo como lo no natural; es el mundo artificial de las cosas y creaciones del hombre, tiene que ver con la 'mundanidad', le concede una medida de permanencia y durabilidad. Acción implica la pluralidad del ser humano, lo que hace que nadie sea igual que otro.

Ahora bien, con la revolución industrial se transforma el trabajo. La división del trabajo implicó que la misma actividad laboral sea sometida a la esfera de lo público. Lo que para los antiguos implicaba las penas y fatigas necesarias para mantener la especie, pasó a ser algo que debía hacerse con excelencia, siendo que en la antigüedad era lo último que se esperaba de él.

A la 'excelencia' (para los griegos ariète y para los romanos virtus) siempre se la relacionó con la esfera de lo público, donde sí cabe sobresalir y distinguirse.

Ahora hacemos con excelencia y en público la labor, mientras que nuestra capacidad para la acción y el discurso ha perdido calidad, ya que el auge de lo social desterró la esfera de lo íntimo y privado.

En la actualidad nos destacamos por nuestro trabajo. Si vamos a una presentación real "soy persona, hija, hermana, madre, pareja...",

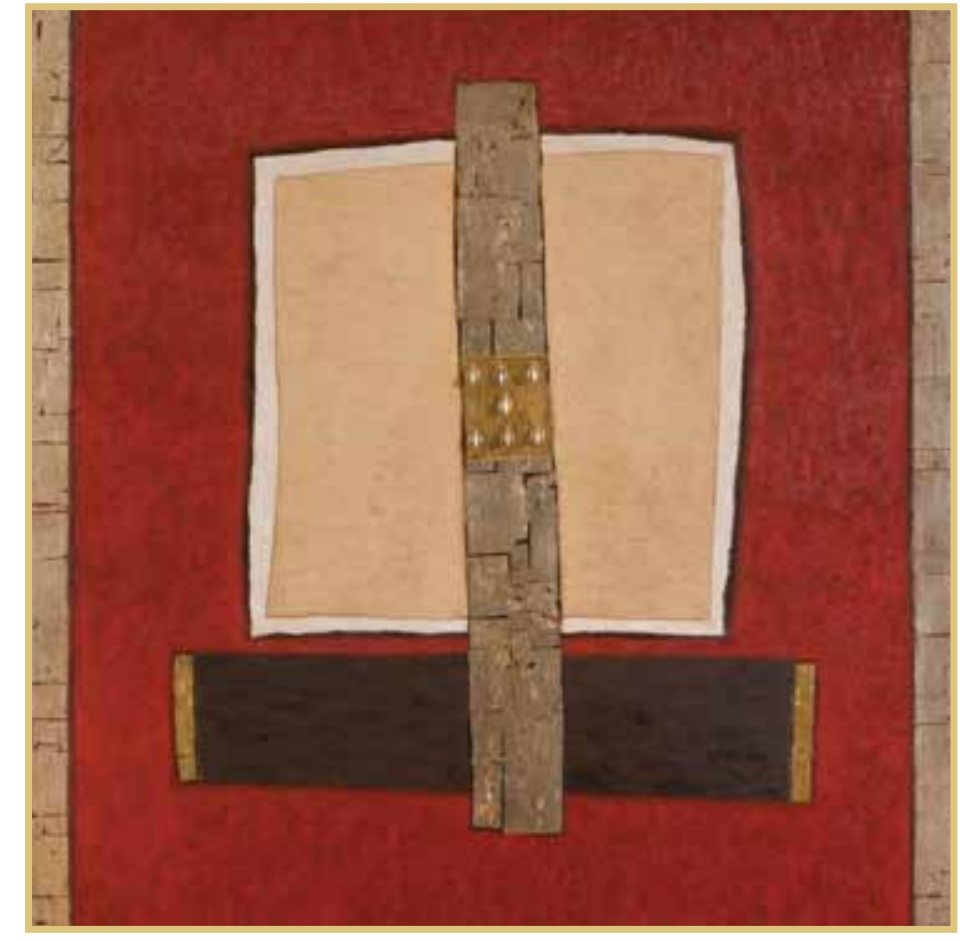

Siete Medallas, Virgen de los Milagros - 2010 $120 \times 120 \mathrm{~cm}$

pero en nuestra sociedad occidental, con claras influencias del positivismo y el funcionalismo, lo que importa es lo que 'se hace', pues aquello termina siendo 'lo que soy'. Por supuesto que determinadas profesiones permitirán alcanzar o no cierta posición social y los demás también nos reconocerán por ello.

Cuando se impone una discapacidad, una de las principales preocupaciones de la persona es responder a la pregunta ¿qué voy a hacer?, pero no como inquietud exclusiva de sustento (lo que sería importante y aceptable en el caso de ser cabeza de familia), sino refiriéndose a ¿qué lugar ocuparé ahora en este medio? A su vez, se evidencia que las personas que rodean al sujeto también lo 'desconocen' como ser social, lo que implica una sensación de 'dejar de pertenecer'.

Son habituales las expresiones: "mis compañeros me llamaban al principio", "mi familia 
hace su vida y yo no sé qué hacer", "estoy todo el día sin hacer nada". Parecería que sin esa ocupación se ha perdido la identidad que ella significaba.

$\mathrm{Al}$ mismo tiempo se empiezan a afectar las relaciones interpersonales, principalmente con la familia cercana, pues perciben una pérdida del espacio adquirido, de su lugar.

No debemos olvidar que como construcción social, la identidad tendrá entonces que reformularse, asentar nuevamente sus bases, reestructurarse para luego poder proyectarse en un futuro.

Es a este proceso al que nos parece importante hacer referencia: cuando el sujeto no puede reconstruir su identidad, pensar nuevamente la pregunta ¿quién soy?, buscando ahora otra respuesta de la que buscó al principio; es imposible que pueda tener éxito en sus emprendimientos futuros. Estamos diciendo que mientras el sujeto no puede 'anexar' la discapacidad como una parte constitutiva de sí mismo, es imposible que pueda perfilar una forma de ser presente.

En ese sentido, creemos importante nuestra participación en el área de rehabilitación, pues como profesoras especiales favorecemos las experiencias y circunstancias que le permiten al sujeto posicionarse de manera diferente con respecto al constructo social de la discapacidad, pudiendo sacarse de encima esa valoración negativa y viéndola como una diferencia que puede aportarle cosas nuevas a su vida.

Debemos tener especialmente en cuenta que el sentimiento de identidad está puesto en peligro por el sentimiento de inoperancia, por lo tanto se hace indispensable la orientación familiar para que permita la preservación de autoestima. La personalidad individual se desarrolla interactuando con los demás; en la comparación con otras personas se cristalizan las particularidades individuales.

Cuando hablamos de baja visión, la complejidad radica que se torna difícil explicarse lo que sucede, porque en general nadie entiende esto de "ver algunas cosas y otras no". Pareciera no haber una clara idea de la 'baja visión' como discapacidad. Esto permite que el sujeto sea el gran simulador, haciendo más difícil su identificación con la discapacidad. Sin embargo siempre llega el momento en que es puesto en evidencia (no vio las escaleras y cayó por ellas o se llevó por delante la mesa donde lo esperaba su novia) y allí llega la situación de crisis, enojo, temor, bronca, miedo al rechazo, etc. En tanto el individuo no acepte la discapacidad como parte de su ser y lo 'comunique', no podrá enfrentar libremente estas situaciones y el porvenir.

Ahora bien, no es fácil decir lo que no se entiende. Es muy complejo esto de afirmar que hay cosas que se pueden ver y otras no, mientras no se puedan observar a través de otros (allí trabajamos también) y definir estas situaciones. Comenzar a entender el funcionamiento permitirá saber cuándo veo y cuándo no. Comunicarlo permitirá ir cambiando la idea que los demás tienen de uno: que soy torpe, distraído, inquieto, etc.

\section{Conclusiones}

No hay que dudar de la importancia de la identidad en el sujeto. En la sociedad de hoy, caracterizada por el individualismo a ultranza, propio de las nuevas corrientes filosóficas como la posmodernidad y la globalización, será cada vez más importante para el sujeto lograr trascender, de alguna manera, la muerte y esto solo será posible a través de la acción pública, en la comunidad, en donde, a parte de caer en la masificación, tenemos la posibilidad de destacarnos.

Cuando se tiene una discapacidad es necesario identificarse con ella positivamente, para creer en las oportunidades que se tiene y así poder actuar, ayudando a generar un 'constructo social de la discapacidad' positivo y dife- 
rente, capaz de valorar la diversidad y respetar al sujeto.

Es muy importante que el sujeto pueda 'valorar-se', pues luego podrá cambiar, de alguna manera, la opinión social sobre la discapacidad y favorecer las futuras identificaciones de otros sujetos, cuyos significantes sociales le devolverán o no una imagen positiva de sí mismo desde el ser como sujeto de acciones, sin atribuirle las noacciones debido a las construcciones negativas con respecto a la discapacidad.

Esta búsqueda de la estructuración de la identidad es esencial a la condición humana y por ende a las personas con discapacidad, como resultado de diversas relaciones entre varios elementos (biológicos, físicos, ambientales, sociales, familiares, etc.). Hay que ayudar a estas personas para que su identidad no quede restringida a unos pocos elementos como aspectos corporales, habilidades y familia. Es preciso que puedan ver lo que les está pasando y desde allí, con los recursos que tengan a su disposición, repensar la vida como construcción. En esa esencia habitará el deseo de encontrar la respuesta a ¿quién soy?

Observamos que en un primer momento lo que aparece es una situación de rechazo, temor y negación de la propia situación, donde ni siquiera aceptan conversar con los demás. Se pone el acento en diferenciarse con el 'yo veo' y el deseo de 'demostrar' que no tienen dificultades para desempeñarse en el medio habitual, aunque hayan llegado por sus propios medios buscando rehabilitarse.

Luego aparece una asimilación de la situación, con negaciones fuera del contexto institucional, pues siguen intentando "parecer personas con vista". Es esta una etapa en que ya han establecido conexión con otros concurrentes, generando redes de relaciones que favorecen y permiten pasar momentos agradables, divertidos y creativos con pares que ven poco o nada. Valoran lo que tienen, pero admiran al que avanza y allí empieza a aflojarse la tensión. Ya no les interesa fingir, ya no temen ser distintos o por lo menos pueden pensarlo. Comienzan a pensar en sí mismos y en lo que necesitan.

Este proceso avanza hasta que asumen su discapacidad o la aceptan. Lejos de negarla, la muestran y la demuestran, incluso no temen "ponerse el cartel y usar un bastón sin importar si es blanco o verde, lo que importa es que lo necesitamos y con él nos sentimos seguros" (palabras de una participante del área de Orientación y Movilidad).

Por lo tanto, 'resignificar' su identidad implica posicionarse en un lugar distinto y a partir de él, el aprendizaje de técnicas y estrategias de autovalimiento para manejarse socialmente se dará en un corto plazo, porque la etapa más dura, la de aceptarse, ya la han superado.

\section{Bibliografía}

- ARENDT, Hannah, La condición humana, Ed. Paidós, Argentina, 1993.

- BERGER, Peter y LUCKMANN Thomas, La construcción social de la realidad, Ed. Amorrortu, Argentina, 1986.

- CORN, Anne, La socialización y los niños con baja visión, Serie de idioma español Hilton Perkins, Montevideo-Uruguay, 1993.

- FOUCAULT, Michel, Hermenéutica del sujeto, Ed. FCE, México, 2001.

- KUUSISTO, Stephen, El planeta de los ciegos, Ed. Plaza-Janes, España, 1999.

- RAMOS, Diana, La identidad social y personal en Sudamérica, Facultad de Psicología de San Sebastián, España, 2008.

- VALERA, Sergi y POL, Enric, El concepto de identidad social urbana, Universitat de Barcelona, España, 1994.

- SUAREZ, Ojeda y Elbio Nestor, "La 'resiliencia' o capacidad de sobreponerse a la adversidad", en: Todos valen, año 1, No. 3, p. 47-51, 1995. 